This article was downloaded by: [Lanssjukhuset Ryhov], [Dirk J onker]

On: 06 October 2011, At: 23: 14

Publisher: Taylor \& Francis

Informa Ltd Registered in England and Wales Registered Number: 1072954 Registered office: Mortimer House, 37-41 Mortimer Street, London W1T 3J H, UK

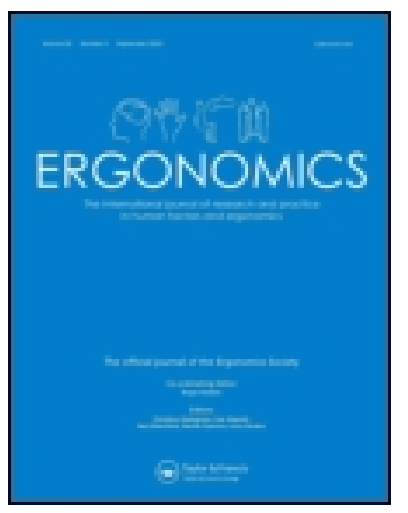

\title{
Ergonomics
}

Publication details, including instructions for authors and subscription information: http:// www.tandfonline.com/loi/terg20

\section{Mechanical exposure among general practice dentists in Sweden and possible implications of rationalisation}

\author{
D. J onker ${ }^{\text {a b }}$, B. Rolander ${ }^{a b}$, I. Balogh ${ }^{c}$, L. Sandsjö ${ }^{d e}$, K. Ekberg $^{a} \&$ J. Winkel ${ }^{f}$ \\ ${ }^{a}$ National Centre for Work and Rehabilitation, Department of Medical Health Sciences, \\ Linköping University, Linköping, Sweden \\ ${ }^{\mathrm{b}}$ Futurum, J önköping, Sweden \\ c Department of Occupational and Environmental Medicine, Lund University, Lund, Sweden \\ ${ }^{d}$ MedTech West/ School of Engineering, University of Borås, Borås, Sweden \\ ${ }^{\mathrm{e}}$ Occupational and Environmental Medicine, Department of Public Health and Community \\ Medicine, The Sahlgrenska Academy at University of Gothenburg, Gothenburg, Sweden \\ ${ }^{f}$ Department of Work Science, University of Gothenburg, Gothenburg, Sweden
}

Available online: 06 Oct 2011

To cite this article: D. J onker, B. Rolander, I. Balogh, L. Sandsjö, K. Ekberg \& J. Winkel (2011): Mechanical exposure among general practice dentists in Sweden and possible implications of rationalisation, Ergonomics, 54:10, 953-960

To link to this article: http:// dx. doi.org/ 10.1080/00140139.2011.606919

\section{PLEASE SCROLL DOWN FOR ARTICLE}

Full terms and conditions of use: http://www.tandfonline.com/page/terms-and-conditions

This article may be used for research, teaching, and private study purposes. Any substantial or systematic reproduction, redistribution, reselling, loan, sub-licensing, systematic supply, or distribution in any form to anyone is expressly forbidden.

The publisher does not give any warranty express or implied or make any representation that the contents will be complete or accurate or up to date. The accuracy of any instructions, formulae, and drug doses should be independently verified with primary sources. The publisher shall not be liable for any loss, actions, claims, proceedings, demand, or costs or damages whatsoever or howsoever caused arising directly or indirectly in connection with or arising out of the use of this material. 


\title{
Mechanical exposure among general practice dentists in Sweden and possible implications of rationalisation
}

\author{
D. Jonker ${ }^{\mathrm{a}, \mathrm{b} *}$, B. Rolander ${ }^{\mathrm{a}, \mathrm{b}}$, I. Balogh $^{\mathrm{c}}$, L. Sandsjö ${ }^{\mathrm{d}, \mathrm{e}}$, K. Ekberg ${ }^{\mathrm{a}}$ and J. Winkel ${ }^{\mathrm{f}}$ \\ ${ }^{a}$ National Centre for Work and Rehabilitation, Department of Medical Health Sciences, Linköping University, Linköping, Sweden; \\ ${ }^{b}$ Futurum, Jönköping, Sweden; ${ }^{c}$ Department of Occupational and Environmental Medicine, Lund University, Lund, Sweden; \\ ${ }^{d}$ MedTech West/School of Engineering, University of Borås, Borås, Sweden; ${ }^{e}$ Occupational and Environmental Medicine, \\ Department of Public Health and Community Medicine, The Sahlgrenska Academy at University of Gothenburg, Gothenburg, \\ Sweden; ${ }^{f}$ Department of Work Science, University of Gothenburg, Gothenburg, Sweden
}

(Received 2 November 2009; final version received 8 July 2011)

\begin{abstract}
The present study investigates the dental work in terms of time distribution and mechanical exposure in value-adding work (VAW) and non-VAW. Further rationalisation of dental work would typically involve an increase in the proportion of VAW. Information on mechanical exposure within the classes of VAW and non-VAW may be used to predict possible implications of rationalisation. Sixteen dentists were investigated. Using a data logger, postures and movements were continuously recorded for each subject during the $4 \mathrm{~h}$ of work, which included the $45 \mathrm{~min}$ of video recording. Time distribution and mechanical exposure for the six different work activities identified were evaluated from the video recordings, using a loss analysis technique. VAW, which comprised $54 \%$ of the total working time, generally implied significantly more constrained mechanical exposures as compared with non-VAW. The results suggest that future rationalisation of dental work, involving a reduction of non-VAW, may increase the risk of developing musculoskeletal disorders.
\end{abstract}

\begin{abstract}
Statement of Relevance: The present study illustrates the potential effects of rationalisation on biomechanical exposures for dentists. The results highlight the significance of integrating ergonomic issues into the rationalisation process in dentistry in addition to ordinary workstation and tool design improvements performed by ergonomists.
\end{abstract}

Keywords: dentistry; efficiency; value-adding; workload

\section{Introduction}

Despite improvements in ergonomics, such as workplace and tool design, work-related musculoskeletal disorders (WMSDs) still represent an important occupational health issue in modern dentistry. A high prevalence of musculoskeletal complaints is especially found in the shoulder/neck and the back (Alexopoulos et al. 2004, Dong et al. 2007, Hayes et al. 2009). Many studies within the health care sector indicate that physical and mental health problems are partly related to the comprehensive rationalisation when implementing new public management (NPM) and human resource management (HRM) (Winkel and Westgaard 1996, Bejerot et al. 1999, Westgaard and Winkel 2011).

Previous studies have shown that long duration of static and constrained body postures occurs during dental work (Finsen et al. 1998, Ratzon et al. 2000, Jonker et al. 2009). However, time aspects of mechanical exposures (risk factors) have rarely been related to the changes in the production system because of rationalisations. Time is a key issue in rationalisation (Brödner and Forslin 2002, Wells et al. 2007, Westgaard and Winkel 2011). Rationalisation may influence time aspects of mechanical exposures by changing duration and distribution of 'value-adding work' (VAW), also called 'direct work' (Engström and Medbo 1997) and non-VAW ('waste'). VAW is defined as the portion of process time that employees spend on actions that create value as perceived by the customer (Keyte and Locher 2004). In industrial production systems, Kazmierczak et al. (2005) and Ostensvik et al. (2008) have shown that non-VAW offers periods of reduced mechanical exposure risk compared with the VAW. According to this, non-VAW represents opportunities for recovery, i.e. the exposure porosity of the working day. Rationalisation by reducing the amount of non-VAW may, thereby, cause 'work intensification' (Westgaard and Winkel 2011).

To obtain a sustainable production system (Docherty et al. 2002, Westgaard and Winkel 2011) with a high proportion of VAW and low risk of

\footnotetext{
*Corresponding author. Email: dirk.jonker@1j.se 
WMSDs, it is essential to improve our insight into the mechanical exposure imposed by VAW and nonVAW. On the basis of the previous studies by Kazmierczak et al. (2005) and Ostensvik et al. (2008), it is hypothesised that non-VAW may also offer an allowance for dentists. Thus, the present study aims to analyse dental work in terms of mechanical exposure in VAW and non-VAW tasks and, hence, to estimate the potential consequences of future rationalisation on mechanical exposure among dentists.

\section{Material and methods}

\subsection{Subjects}

Sixteen dentists were included in the study, 10 women and 6 men. The mean age of the participants was 49 years (range: 39-59). All were right handed and employed in public dental clinics in Jonkoping County, Sweden. They had worked as dentists for an average of 22 years (range: 9-34). Their average weekly working hours were $37 \mathrm{~h}$ (range: 30-40).

\subsection{Methods}

Data were collected during an ordinary working day, at the dentist's normal workplace, by means of a digital video camera (Canon MVX30i) and direct measurements of mechanical exposure synchronised to video recordings. Work activities were assessed from the videos to identify the tasks that constituted dental work, and corresponding task-specific exposures were obtained, as described below.

\subsubsection{Mechanical exposure}

Inclinometers were used to record the flexion/extension of the head and trunk and the elevation of the upper arms relative to the line of gravity for the first $4 \mathrm{~h}$ of the dentist's working day. A data logger, with a sampling rate of $20 \mathrm{~Hz}$, was used for data acquisition (Logger Teknologi HB, Åkarp, Sweden; Hansson et al. 2006).

Analyses of the inclinometer data were performed using PC-based programmes (Department of Occupational Medicine, Lund University Hospital, Lund). Positions and angular velocities were calculated. Postures and movements for each category of activity were obtained by synchronising video and mechanical exposure recordings (Forsman et al. 2002).

One inclinometer was placed on the forehead, and another to the right of the cervical-thoracic spine at the level of cervical vertebrae 7 (Figure 1). For the upper arms, the inclinometers were fixed to plastic plates $\left(55 \times 27 \mathrm{~mm}^{2}\right)$ that were placed along the upper arm, with the lateral edge along the line from

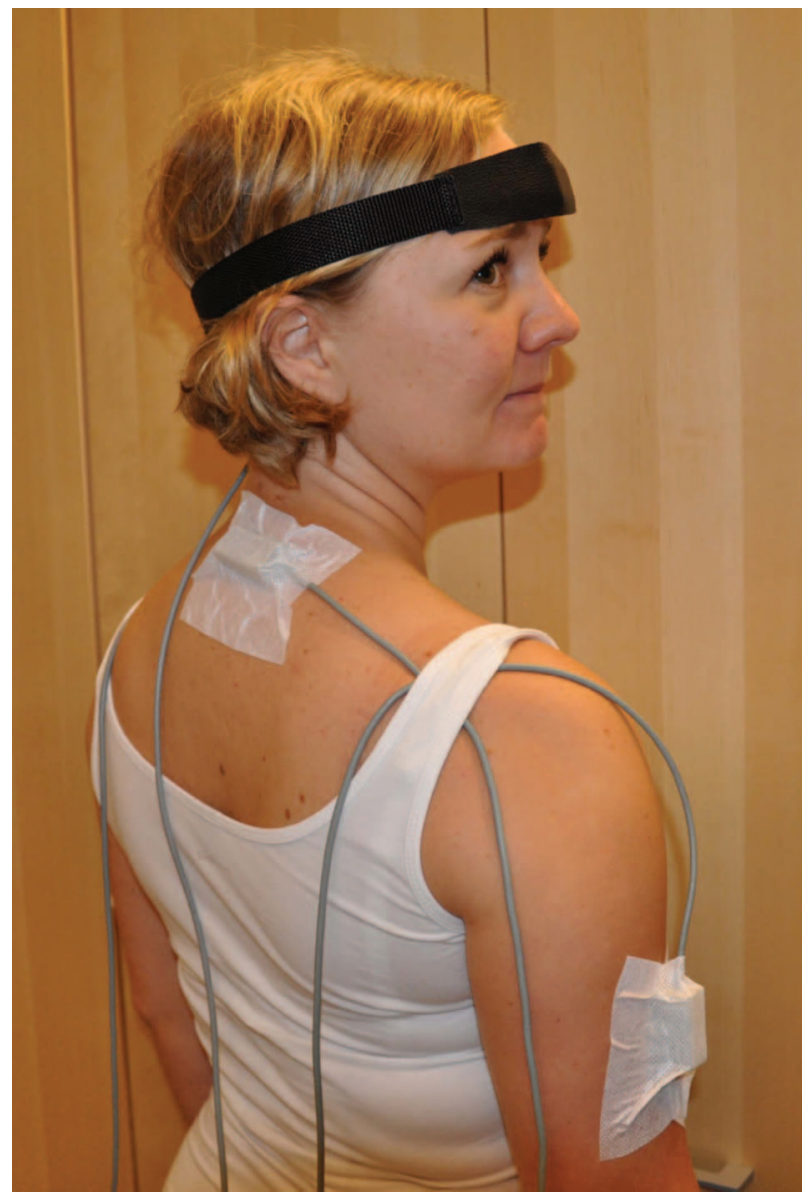

Figure 1. Inclinometers attached to a dentist.

the lateral posterior corner of the acromion to the lateral epicondyle and with the upper edge at the insertion of the deltoid muscle (Hansson et al. 2006). Chirurgical tape was used to secure fixation of trunk and arm inclinometers to the skin thus minimising interference with clothing. An adjustable headband was used to fixate the head inclinometer.

Initially, a calibration procedure was performed for each subject. During $5 \mathrm{~s}$, a reference position was established for the head, upper back and upper arms. The reference position for the head and upper back $\left(0^{\circ}\right.$ flexion) was defined as the position obtained when the subject was standing, looking at a mark at eye level. The forward direction of the head and back was defined with the subject sitting, leaning straight forward and looking at the floor (Hansson et al. 2006). For the reference position of the upper arms, an elevation of $0^{\circ}$ was recorded with the side of the body leaning against the backrest of a chair, the arm hanging perpendicular over the backrest of the chair and with a dumbbell of $2 \mathrm{~kg}$ in the hand. 


\subsubsection{Video recordings and activity analysis}

During the first $45 \mathrm{~min}$ of the 4-h recording of direct mechanical exposure, the dentist's work activities were also registered by means of a video recorder. The video recorder was switched off during coffee breaks. Work activities were documented (sampling frequency $1 \mathrm{~Hz}$ ) by means of a video activity analysis system ('Videolys' system; Chalmers University of Technology; Engström and Medbo 1997). All working days of the week were represented during the video recordings.

Initially, different work descriptions were derived and coded directly from the video recordings (Table 1). In the next stage, work activities were defined in accordance with the so-called zero-based analysis (Engström and Medbo 1997). The activity analyses were used to estimate the 'shop-floor' work efficiency of dental work in terms of VAW and non-VAW (Keyte and Locher 2004).

In the present study, VAW was operationalised according to Neumann et al. (2006). This represents an engineering approach used in assembly work and includes any assembly work and acquisition of components or tools that can be completed without the operators having to move from their assembly position. In our study, VAW was, thus, operationalised as all intra-oral patient work and all treatment related dialogue with the patient without leaving the 'working position' as defined by Rundcrantz et al. (1990). Periods of disturbances caused by the researchers were identified and excluded from further analyses.

In the present study, reliability of the work activity analysis was assessed according to Kazmierczak et al. (2006). The time history agreement between two researchers who made initial independent analyses of five subjects (i.e. $3 \mathrm{~h}$ and $45 \mathrm{~min}$ ) of the video recordings was $82 \%$. One researcher then analysed all the remaining video recordings.

\subsection{Data analysis}

Descriptive statistics are presented as means $(\mathrm{m})$, and 95\% confidence intervals (CI 95\%). For the inclinometry data, group means of the 50th percentile and group means of differences between 90th and 10th percentiles were used to estimate variation in velocities and postures (Kazmierczak et al. 2005).

To compare the different work activities, the analysis of variance (ANOVA) test for repeated measurements, adjusted for multiple comparisons by the Bonferroni method (Douglas and Altman 1999), was used for angular positions, velocities and differences between 90th and 10th percentiles of the head, back and upper arms. Fifteen tests were carried out on each body part, and, therefore, the $\alpha$ level for each individual test was adjusted by the Bonferroni method to 0.003 . By using the Bonferroni correction, the $\alpha$ level for the individual tests was adjusted downwards to ensure that the overall experiment-wise risk for the number of tests remained at 0.05 .

Paired-samples $t$ tests were used to detect the differences in postures and movements on job level between the $45 \mathrm{~min}$ of video recordings and the $4 \mathrm{~h}$ of inclinometry registration.

Significance was assumed at $\alpha$ level of 0.05. All statistical calculations were performed using SPSS (Chicago, IL 60606, version 16.0).

\section{Results}

\subsection{Task distribution}

VAW comprised $54 \%$ of the total observed time. The major part $(85 \%)$ of the VAW consisted of 'patient treatment'. Figure 2 illustrates the task distribution for the recorded periods of dentist work.

Table 1. Classification and description of activities in the work tasks.

\begin{tabular}{|c|c|c|}
\hline Classification & Work tasks & Description \\
\hline \multirow[t]{3}{*}{ VAW } & Patient treatment & $\begin{array}{l}\text { Principal activities during patient dental treatment, e.g. dental examination, } \\
\text { dental filling therapy, tooth extraction, assessing X-ray pictures and reading } \\
\text { patient's journal during dental treatment and reaching for tools and } \\
\text { materials during dental patient treatment. }\end{array}$ \\
\hline & Dental information & Dentist's information about treatment during the dental treatment. \\
\hline & & $\begin{array}{l}\text { Conversation about dental treatment with patient or relatives to the patient } \\
\text { during treatment. }\end{array}$ \\
\hline \multirow[t]{4}{*}{ Non-VAW } & X-ray handling & Taking X-ray pictures, assessing and storing. \\
\hline & Administration & Writing/reading and dictation to the patient file. \\
\hline & Handling parts and materials & $\begin{array}{l}\text { Adjusting patient and/or operator chair, handling of tools/materials, } \\
\text { Hand hygiene. }\end{array}$ \\
\hline & Disturbances & $\begin{array}{l}\text { Transfers of the dentist in the dental practice. Walking to the next patient. } \\
\text { Short spontaneous breaks during treatment lasting for more than } 1 \mathrm{~s} \text {. } \\
\text { Social communication with patients or colleagues. } \\
\text { Waiting. }\end{array}$ \\
\hline
\end{tabular}




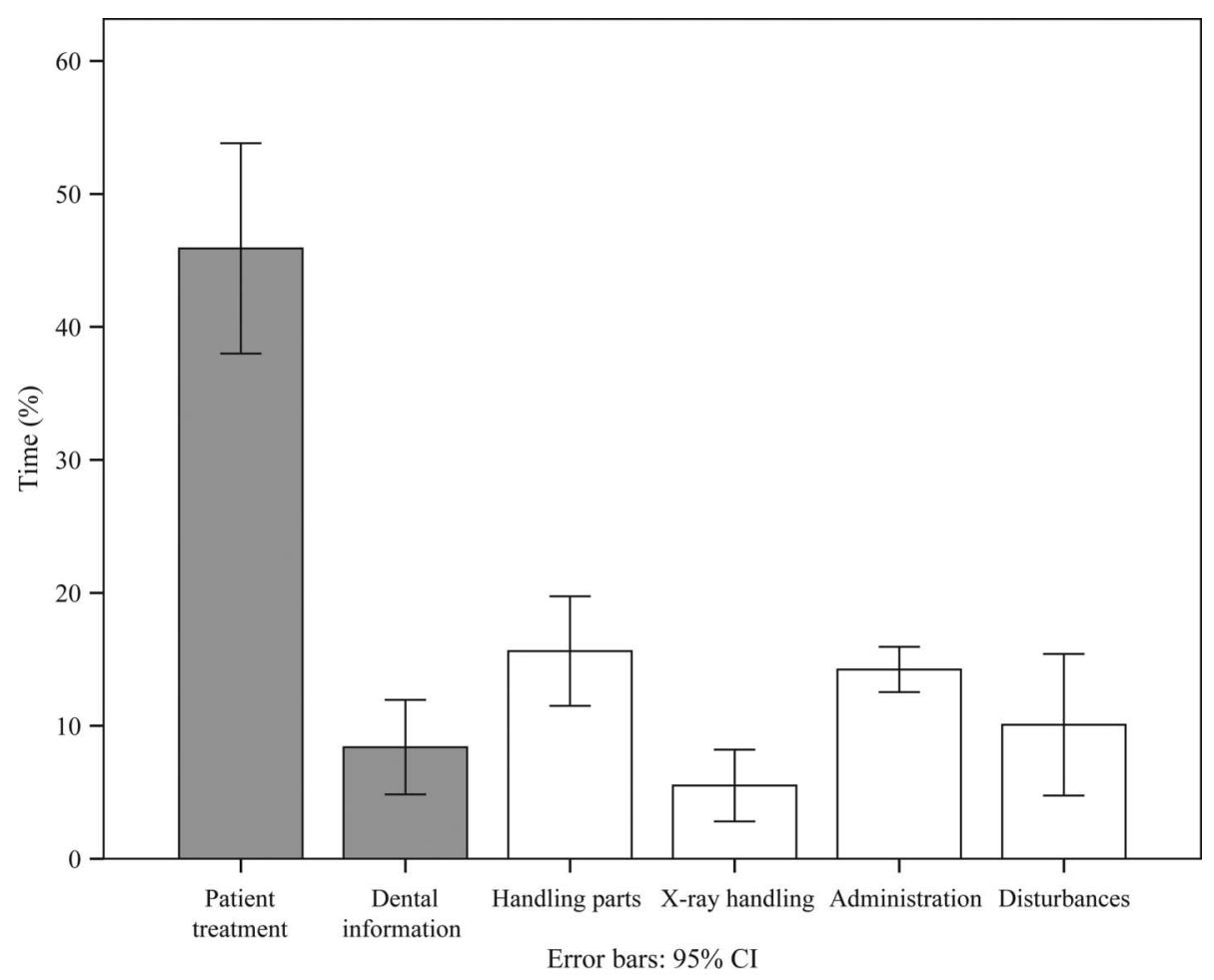

Figure 2. Mean distribution of the total time consumption according to task categories. Grey bars represent VAW; white bars non-VAW. $N=16$.

\subsection{Work postures}

The ANOVA test for repeated measurements showed that 'patient treatment', which was a major part of VAW, implied a significantly more flexed posture of the head compared with all the other investigated work tasks. The median head flexion angle was $39.9^{\circ}$, compared with $19.5^{\circ}$ during 'administration' and 'disturbances'. For the back, 'patient treatment' implied significantly more forward flexion than 'handling parts and materials'. The work postures of the right and left upper arms were, in general, not significantly influenced by any of the investigated work tasks. With the exception of 'administration' and 'dental information', the range in position of the head, i.e. the difference between 10th and 90th percentiles, was significantly smaller in 'patient treatment' compared with the other investigated work tasks. The work postures during the observed work tasks are shown in Table 2.

\subsection{Angular velocities}

The 'patient treatment' task implied generally lower medium movement velocities and smaller velocity ranges (90th-10th percentiles) for the head and back as compared with the other investigated work tasks. The medium angular velocities and velocity ranges (90th-10th percentiles) of the upper arms were also generally lower and smaller during this task. In particular, medium movement velocities and velocity ranges (90th-10th percentiles) of the right upper arm were lower and smaller during 'patient treatment' compared with 'handling parts and materials'. Furthermore, the medium movement velocities and velocity ranges (90th-10th percentiles) of the left upper arm during 'patient treatment' was significantly lower and smaller as compared with the other investigated work tasks, with the exception of 'administration' and 'handling X-ray pictures'. Angular velocities during the observed work tasks are shown in Table 3.

\section{Discussion}

The main findings of this study were that VAW tasks comprised $54 \%$ of the dentists' total working time. The major part of the VAW consisted of patient treatment $(85 \%)$, which generally implied slower angular velocities for the head, back and upper arms, and more flexed postures of the head, compared with the nonVAW. Future rationalisations may imply reduced duration of non-VAW, thus causing a work intensification and, thereby, an increased risk of developing WMSD. 
Table 2. Postures $\left({ }^{\circ}\right)$ assessed for each of the investigated tasks and the job as a whole. Positive angles denote forward flexion for both head and back. $N=16$.

\begin{tabular}{|c|c|c|c|c|}
\hline & $\begin{array}{l}\text { Head angle, } \\
\text { back-forward }\end{array}$ & $\begin{array}{c}\text { Back angle, } \\
\text { back-forward }\end{array}$ & $\begin{array}{l}\text { Right upper } \\
\text { arm elevation }\end{array}$ & $\begin{array}{l}\text { Left upper } \\
\text { arm elevation }\end{array}$ \\
\hline \multicolumn{5}{|l|}{ Patient treatment } \\
\hline m 50th & $39.3[31.7-46.9]$ & $20.0[13.5-26.5]$ & $28.5[22.5-34.5]$ & $33.0[22.8-43.4]$ \\
\hline$m$ diff 90th-10th & $30.4[23.9-36.8]$ & $17.5[13.9-21.1]$ & $32.7[22.7-42.6]$ & 27.1 [18.2-35.9] \\
\hline \multicolumn{5}{|l|}{ Dental information } \\
\hline m 50th & $24.3[13.1-35.5]^{1}$ & $17.3[10.2-24.5]$ & $29.6[18.8-40.5]$ & 30.5 [21.6-39.4] \\
\hline$m$ diff 90th-10th & $35.6[25.4-45.8]$ & $22.4[16.0-28.8]$ & $35.6[20.5-50.8]^{b}$ & $22.7[18.5-27.0]^{\mathrm{c}}$ \\
\hline \multicolumn{5}{|l|}{ X-ray handling } \\
\hline $\begin{array}{l}m \text { 50th } \\
m \text { diff } 90 \text { th-10th }\end{array}$ & $\begin{array}{l}23.2[7.6-38.8]^{1} \\
394[330-459]^{\mathrm{a}}\end{array}$ & $16.1[7.2-24.9]$ & $28.7[21.0-36.3]{ }_{b}$ & $\begin{array}{l}32.7[20.7-44.7] \\
27.6[17.4-37.7]\end{array}$ \\
\hline \multicolumn{5}{|l|}{ Administration } \\
\hline m 50th & $19.5[8.7-30.3]^{1}$ & $16.1[8.1-24.0]$ & $29.7[21.8-37.6]$ & $27.5[17.3-37.7]$ \\
\hline$m$ diff 90th-10th & $37.1[28.3-46.0]$ & 18.5 [8.8-28.3] & $20.0[13.3-26.7]^{\mathrm{a}}$ & 19.5 [10.3-28.6] \\
\hline \multicolumn{5}{|l|}{ Handling parts and materials } \\
\hline$m$ diff 90 th-10th & $44.3[36.7-51.8]^{\mathrm{a}}$ & $26.8[20.1-33.6]^{\mathrm{a}}$ & $34.7[28.2-41.2]^{b}$ & $30.0[24.1-36.0]^{\mathrm{b}}$ \\
\hline \multicolumn{5}{|l|}{ Disturbances } \\
\hline m 50th & $19.5[7.9-31.1]^{1}$ & 13.9 [6.9-20.9] & $26.0[19.8-32.2]$ & $27.5[17.8-37.3]$ \\
\hline$m$ diff 90th-10th & $42.3[34.5-50.0]^{\mathrm{a}}$ & $26.1[15.8-36.4]^{\mathrm{b}}$ & $26.7[20.2-33.1]^{\mathrm{c}}$ & $24.1[18.6-29.7]$ \\
\hline \multicolumn{5}{|l|}{ Job } \\
\hline $4 \mathrm{~h}$ & $28.9[23.7-34.0]^{\mathrm{d}}$ & 16.4 [12.5-20.3] & $28.5[25.0-32.0]$ & 30.4 [25.6-35.2] \\
\hline $45 \mathrm{~min}$ & $32.1[27.0-37.2]$ & $17.0[13.3-20.8]$ & $28.0[24.6-31.4]$ & $31.7[26.7-36.8]$ \\
\hline
\end{tabular}

Note: Tasks: Group means of 50th percentile and of differences between 90th and 10th percentiles [CI 99.7\% in brackets] for the head, back and upper arms, during the 45 min of video recording. Job: Group means of 50th percentile [CI 95\% in brackets] for the head, back and upper arms, during the $45 \mathrm{~min}$ of video recording and $4 \mathrm{~h}$ of dental work. ANOVA for repeated measurements, adjustment for multiple comparisons by the Bonferroni method to $\alpha$ level of 0.003 . Paired $t$ test for differences between 45 min of video recordings and $4 \mathrm{~h}$ of inclinometry registration. $p<0.05$. ${ }^{1}$ Significant difference for $\mathrm{m}$ 50th from patient treatment. ${ }^{\mathrm{a}}$ Significant difference for $\mathrm{m}$ diff 90 th-10th from patient treatment. ${ }^{b}$ Significant difference for $\mathrm{m}$ diff 90 th-10th from administration. ${ }^{\mathrm{c}}$ Significant difference for $\mathrm{m}$ diff 90 th-10th from handling parts and materials. ${ }^{\mathrm{d}}$ Significant difference compared with video registration.

Table 3. Angular velocities $(\% / \mathrm{s})$ assessed for each of the investigated tasks and the job as a whole. $N=16$.

\begin{tabular}{|c|c|c|c|c|}
\hline & $\begin{array}{l}\text { Head angle, } \\
\text { back-forward }\end{array}$ & $\begin{array}{l}\text { Back angle, } \\
\text { back-forward }\end{array}$ & $\begin{array}{l}\text { Right upper } \\
\text { arm elevation }\end{array}$ & $\begin{array}{l}\text { Left upper } \\
\text { arm elevation }\end{array}$ \\
\hline \multicolumn{5}{|l|}{ Patient treatment } \\
\hline $\begin{array}{l}m \text { 50th } \\
m \text { diff } 90 \text { th-10th }\end{array}$ & $3.6[2.7-4.4]$ & $2.7[2.1-3.4]$ & $7.7[5.5-9.9]$ & $5.5[3.9-7.2]$ \\
\hline \multicolumn{4}{|l|}{ Dental information } & $30.7[23.5-37.8]$ \\
\hline$m$ 50th & $7.9[4.6-11.3]^{1}$ & $5.6[3.1-8.0]^{1}$ & $14.7[6.9-22.3]$ & $11.1[6.3-16.0]^{1}$ \\
\hline$m$ diff 90th-10th & $44.1[27.9-60.3]^{\mathrm{a}}$ & $28.1[18.3-37.9]^{\mathrm{a}, \mathrm{c}}$ & $69.2[44.8-93.6]$ & $52.7[34.7-70.8]^{\mathrm{a}, \mathrm{c}}$ \\
\hline \multicolumn{4}{|l|}{ X-ray handling } & $11.5[3.5-19.5]$ \\
\hline$m$ diff $90 \mathrm{th}-10 \mathrm{th}$ & $40.5[28.0-53.1]^{\mathrm{a}}$ & $31.1[21.0-41.2]^{\mathrm{a}}$ & $74.1[52.9-95.3]^{\mathrm{a}}$ & $64.1[40.7-87.4]^{\mathrm{a}}$ \\
\hline Administration & $4.8[3.7-5.8]^{1}$ & $3.2[2.2-4.2]^{1}$ & $8.7[5.8-11.7]$ & $7.0[4.3$ \\
\hline$m$ diff 90th-10th & $33.0[25.7-40.3]^{\mathrm{a}}$ & $22.2[15.8-28.6]^{\mathrm{a}}$ & $55.0[39.9-70.2]^{\mathrm{a}}$ & $44.4[31.6-57.3]^{\mathrm{a}}$ \\
\hline Handling parts and materials & $9.3[5.0-13.7]^{1,2}$ & $6.8[3.2-10.4]^{1,2}$ & $19.7[9.9-29.4]^{1,2}$ & $16.6[7.9-25.3]^{1,2}$ \\
\hline $\begin{array}{l}m \text { diff } 90 t h-10 t h \\
\text { Disturbances }\end{array}$ & $52.2[34.2-70.1]^{\mathrm{a}, \mathrm{b}}$ & $37.3[24.3-50.4]^{\mathrm{a}, \mathrm{b}}$ & $87.8[62.9-112.8]^{\mathrm{a}, \mathrm{b}}$ & $74.3[52.1-96.4]^{\mathrm{a}, \mathrm{b}}$ \\
\hline m 50th & $8.8[4.1-13.7]^{1}$ & $6.3[2.4-10.1]^{1}$ & $17.4[5.0-29.8]$ & $15.1[5.4-24.8]^{1}$ \\
\hline \multicolumn{5}{|l|}{ Job } \\
\hline $4 h$ & $5.3[4.4-6.1]$ & $3.6[3.0-4.2]$ & $9.7[8.2-11.3]$ & $7.8[6.4-9.3]$ \\
\hline $45 \mathrm{~min}$ & $5.0[4.2-5.7]$ & $3.5[2.9-4.0]$ & $9.7[8.2-11.0]$ & $7.6[6.3-8.7]$ \\
\hline
\end{tabular}

Note: Tasks: Group means of 50th percentile and of differences between 90th and 10th percentiles [CI 99.7\% in brackets] for the head, back and upper arms, during the 45 min of video recording. Job: Group means of 50th percentile [CI 95\% in brackets] for the head, back and upper arms, during the $45 \mathrm{~min}$ of video recording and $4 \mathrm{~h}$ of dental work. ANOVA for repeated measurements, adjustment for multiple comparisons by the Bonferroni method to $\alpha$ level of 0.003 . Paired $t$ test for differences between 45 min of video recordings and $4 \mathrm{~h}$ of inclinometry registration. $p<0.05 .{ }^{1}$ Significant difference for $\mathrm{m}$ 50th from patient treatment. ${ }^{2}$ Significant difference for $\mathrm{m}$ 50th from administration. ${ }^{\mathrm{a}}$ Significant difference for $\mathrm{m}$ diff 90 th-10th from patient treatment. ${ }^{\mathrm{b}}$ Significant difference for $\mathrm{m}$ diff 90 th-10th from administration.

${ }^{\mathrm{c}}$ Significant difference for $\mathrm{m}$ diff 90 th-10th from handling parts and materials. 


\subsection{Methodological considerations}

\subsubsection{Exposure assessments}

In the present study, detailed information on mechanical exposures has been evaluated by combining direct measurements and video-based observations of work task distribution according to the previously described procedures. This enables exposure assessments of VAW and non-VAW and may thus allow predictions of future changes in job exposure because of rationalisations in dentistry. However, our waste assessments were confined to one job level (dentists), thus overlooking waste reductions in the other jobs within dentistry. The latter may increase the average productivity per dentist without causing work intensification among dentists (cf. Rolander 2010).

By using the standardised video observer training procedure suggested by Kazmierczak et al. (2006), we managed to improve our between-observer reliability to about the same level as they obtained. This was classified as 'good agreement' in their studies.

The procedure used for the direct exposure assessment (inclinometers and logger system) has previously shown good precision and high reliability (Hansson et al. 2006). In addition, the data were obtained during normal work in the field to improve external validity. In total, 16 dentists were registered, and all working days of the week were represented. Only working postures and movements were measured. In a study by Dong et al. (2007), a significant interaction was shown between the design of different dental tools and measured physical workload in the lower arms during simulated dental work. The effect of such forces during dental work has not been considered in this study.

The representativity of only $45 \mathrm{~min}$ of video recordings may be questioned. However, postures and movements were also continuously recorded for each subject during $4 \mathrm{~h}$. When comparing the mechanical exposure assessed during the $45 \mathrm{~min}$ of video recordings with the $4 \mathrm{~h}$ of continuous registration, only one minor significant difference was found for the group mean of the median head posture: during the $4 \mathrm{~h}$ of registration, it was $28.9^{\circ}$ (CI 95\% $=23.7-34.0^{\circ}$ ) compared with $32.1^{\circ}$ (CI 95\% $=27.0-37.2^{\circ}$ ) for the 45 min of video recording (Tables 2 and 3). This may suggest some overrepresentation of the work task 'patient treatment' during the video recordings. Mathiassen and Svendsen (2009) found that sample duration longer than $40 \mathrm{~min}$ is needed to reduce mechanical exposure bias to below $25 \%$ of true whole-day exposure when studying arm movements among house painters. However, the investigated exposure ranges among dentists are presumed to be smaller compared with the range of movements among housepainters. This suggests a corresponding smaller overall mechanical job exposure bias in our study.
According to this, we found, in general, a good agreement between our exposure data on the basis of the recordings during $45 \mathrm{~min}$ and $4 \mathrm{~h}$, respectively.

The applied classification of tasks into VAW and non-VAW was developed for industrial production systems (Engström and Medbo 1997, Liker 2004) In our study, VAW was operationalised as all activities which could be completed without the dentist having to move away from the patient (cf. Neumann et al. 2006). Consequently, some typical work tasks usually carried out by a dentist, such as 'assessing X-ray pictures while not in work position', were not considered as VAW. Because of this methodical drawback, the proportion of VAW may have been slightly underestimated. In addition, the industrial production perspective that is commonly used in healthcare services does not consider the contribution of the patient in value creation, e.g. in terms of quality of treatment perceived by the patient (Grönroos and Ojasalo 2004).

\subsection{Task exposures and rationalisation}

Patient treatment comprises a major part $(85 \%)$ of the VAW time. During patient treatment, the group mean of the 50th percentile of the head flexion was $39.3^{\circ}$. The increased risk of developing WMSD when the forward head flexion exceeds $20-30^{\circ}$ during a prolonged period of time has been known for several decades (Bernard 1997, Kroemer and Grandjean 1997, Ariens et al. 2001). The angular velocities for the head, back and upper arms were significantly lower and the differences between the 90th and the 10th percentiles smaller, compared with the other work tasks. The figures for angular velocities are in line with that of modern industrial assembly work (Christmansson et al. 2002, Balogh et al. 2006). Low angular velocities are explained by high precision demands and, thereby, sustained stabilising contractions of the agonist and antagonist of muscles around the joints. According to this, Rolander et al. (2005) and Jonker et al. (2009) have shown negative correlations between angular velocities and perceived work load among dentists. The combination of awkward postures and low angular velocities during a prolonged time seems to increase the risk for shoulder/neck complaints (Nordander et al. 2009, Hansson et al. 2010). This means that the major part of VAW is characterised by more constrained working conditions, compared with the nonVAW.

The task 'dental information' has been considered as VAW in this study. During this task, the head was kept in a more upright position and the angular velocity and the range of velocity (diff 90th-10th) were significantly higher and wider, respectively, compared 
with the other type of VAW, i.e. patient treatment. Thus, 'dental information' implies a less constrained mechanical exposure compared with 'patient treatment'.

'Handling parts and materials' comprised the major part of the non-VAW. During this task, all mean velocities were significantly higher and the range of velocities wider, compared with both 'patient treatment' and 'administration'. This indicates a more dynamic mechanical exposure during this task.

Table 4 indicates more constrained postures for the head, back and upper arms during VAW for the dentists compared with the industrial assembly workers. In general, the angular velocities were three to four times lower for the dentists assessed by similar analytical methods. In addition, the VAW for the dentists implied more forward flexion of the head and back, compared with both material picking (Christmansson et al. 2002) and car disassembly work (Kazmierczak et al. 2005). All together, these comparisons suggest more riskful mechanical exposures during dental VAW compared with the industrial work (cf. NRC 2001).

Furthermore, considering the angular velocities of the right upper arm, both the very low angular velocities for dentists in the present study $\left(8.6^{\circ} / \mathrm{s}\right)$, and the high angular velocities for assembly workers $\left(52.0^{\circ} / \mathrm{s}\right)$ seem to be associated with a high prevalence of WMSD in the shoulder/neck region (Christmansson et al. 2002, Alexopoulos et al. 2004, Dong et al. 2007, Hayes et al. 2009). For car disassembly workers, the angular velocity was $21 \%$ and the prevalence of WMSD in the shoulder/neck region seemed to be modest (Kazmierczak 2005). This supports the concept of a U-shaped relationship between this aspect of

Table 4. Mechanical exposure data during VAW from three different occupations. Group means of 50th percentile.

\begin{tabular}{|c|c|c|c|}
\hline & $\begin{array}{c}\text { Present } \\
\text { study, } \\
\text { dentists } \\
N=16\end{array}$ & $\begin{array}{l}\text { Christmansson } \\
\text { et al. }(2002), \\
\text { material } \\
\text { pickers } \\
N=4\end{array}$ & $\begin{array}{l}\text { Kazmierczak } \\
\text { et al. }(2005), \\
\text { car disassembly } \\
\text { workers } \\
N=10\end{array}$ \\
\hline \multicolumn{4}{|l|}{ Head } \\
\hline Postures $\left(^{\circ}\right)$ & 38 & 33 & 30 \\
\hline Velocities $(\% / \mathrm{s})$ & 4.2 & 15 & 20 \\
\hline \multicolumn{4}{|l|}{ Back } \\
\hline Postures $\left({ }^{\circ}\right)$ & 19 & 14 & 10 \\
\hline Velocities $(\% / \mathrm{s})$ & 2.9 & 12 & 14 \\
\hline \multicolumn{4}{|l|}{ Right arm } \\
\hline Postures $\left(^{\circ}\right)$ & 28 & 29 & 38 \\
\hline Velocities $(\% / \mathrm{s})$ & 8.4 & 52 & 21 \\
\hline \multicolumn{4}{|l|}{ Left arm } \\
\hline Postures $\left({ }^{\circ}\right)$ & 33 & 26 & - \\
\hline Velocities $(\% / \mathrm{s})$ & 6.0 & 42 & - \\
\hline
\end{tabular}

mechanical exposure and the risk of developing WMSD, as previously suggested by Winkel and Westgaard (1992).

\subsection{Expected effects of rationalisation}

In the present study of dentists, VAW was estimated to comprise $54 \%$ of the working day. In the studies of old-fashioned car disassembly, VAW comprised about 30\% (Kazmierczak et al. 2005); in modern industrialised work, motor and sewing machine assembly, it comprised about 70\% (Bao et al. 1996, Neumann et al. 2006). Thus, the percentage of VAW in the present study is approximately $15-20 \%$ units lower compared with the industrial assembly work.

Compared with the industrial work, there may be a potential for future rationalisation. The introduction of NPM, HRM and other similar management strategies in Swedish public dental care has contributed to the development of more business-like dentistry exposed to market conditions (Winkel and Westgaard 1996, Bejerot et al. 1999, Almqvist 2006). A major aim of rationalisation is to reduce non-VAW and make more efficient use of time (Wild 1995, Brödner and Forslin 2002); future rationalisations in Swedish dentistry may thus increase the time spent in VAW. This may increase the proportion of VAW. The present data suggest that this may reduce the exposure porosity (i.e. a work intensification) which, in turn, may increase the risk of developing WMSD among dentists. However, it remains to be investigated if this would be possible given the interactive nature required with the patient in dentistry.

\section{References}

Alexopoulos, E.C., Stathi, I.C., and Charizani, F., 2004. Prevalence of musculoskeletal disorders in dentists. $B M C$ Musculoskeletal Disorders, 5, 16.

Almqvist, R., 2006. New public management, - om konkurrensutsättning, kontrakt och kontroll. Malmö: Liber.

Ariens, G.A., et al., 2001. Are neck flexion, neck rotation, and sitting at work risk factors for neck pain? Results of a prospective cohort study. Occupational and Environmental Medicine, 58 (3), 200-207.

Balogh, I., et al., 2006. Increasing the degree of automation in a production system: consequences for the physical workload. International Journal of Industrial Ergonomics, 36, 353-365.

Bao, S., Mathiassen, S.E., and Winkel, J., 1996. Ergonomic effects of a management-based rationalization in assembly work - a case study. Applied Ergonomics, 27 (2), 89-99.

Bejerot, E., et al., 1999. Perceived control systems, work conditions, and efficiency among Swedish dentists: interaction between two sides of human resource management. Acta Odontologica Scandivania, 57 (1), $46-54$. 
Bernard, B.P., 1997. Musculoskeletal disorders and workplace factors. A critical review of epidemiologic evidence for work-related musculoskeletal disorders of the neck, upper extremity, and lower back. Cincinnati, $\mathrm{OH}$ : National Institute for Occupational Safety and Health (NIOSH).

Brödner, P. and Forslin, J., 2002. O tempora, o mores! Work intensity - why again an issue? In: P. Dochety, ed. Creating sustainable work systems: emerging perspectives and practice. London: Taylor \& Francis Books Ltd, 2648.

Christmansson, M., et al., 2002. A case study of principally new way of materials kitting - an evaluation of time consumption and physical workload. International Journal of Industrial Ergonomics, 30, 49-65.

Docherty, P., Forslin, J., and Shani, A.B., 2002. Creating sustainable work systems: emerging perspectives and practice. London: Routledge.

Dong, H., et al., 2007. The effect of tool handle shape on hand muscle load and pinch force in a simulated dental scaling task. Applied Ergonomics, 38 (5), 525-531.

Douglas, G.A., 1999. Practical statistics for medical research. New York: Chapman \& Hall/CRC, 211.

Engström, T. and Medbo, P., 1997. Data collection and analysis of manual work using video recording and personal computer techniques. International Journal of Industrial Ergonomics, 19, 291-298.

Finsen, L., Christensen, H., and Bakke, M., 1998. Musculoskeletal disorders among dentists and variation in dental work. Applied Ergonomics, 29 (2), 119-125.

Forsman, M., et al., 2002. A method for evaluation of manual work using synchronised video recordings and physiological measurements. Applied Ergonomics, 33 (6), 533-540.

Grönroos, C. and Ojasalo, P., 2004. Service productivity towards an conceptualization of the transformation of economic results in service business. Journal of Business Research, 57, 414-423.

Hansson, G.A., et al., 2006. Precision of measurements of physical workload during standardised manual handling. Part 2. Inclinometry of head, upper back, neck and upper arms. Journal of Electromyography and Kinesiology, 16 (2), 125-136.

Hansson, G.A., et al., 2010. Physical workload in various types of work. Part 2. Neck, shoulder and upper arm. International Journal of Industrial Ergonomics, 40 (3), 267-281.

Hayes, M., Cockrell, D., and Smith, D.R., 2009. A systematic review of musculoskeletal disorders among dental professionals. International Journal of Dental Hygiene, 7 (3), 159-165.

Jonker, D., Rolander, B., and Balogh, I., 2009. Relation between perceived and measured workload obtained by long-term inclinometry among dentists. Applied Ergonomics, 40 (3), 309-315.

Kazmierczak, K., 2005. Industrial development of car disassembly - ergonomics and system performance. Thesis (PhD). Department of Industrial Management, School of Mechanical Engineering, Lund Institute of Technology and National Institute for Working Life, Sweden.

Kazmierczak, K., et al., 2005. An integrated analysis of ergonomics and time consumption in Swedish 'craft-type' car disassembly. Applied Ergonomics, 36 (3), 263-273.

Kazmierczak, K., et al., 2006. Observer reliability of industrial activity analysis based on video recordings. International Journal of Industrial Ergonomics, 36, 275282.
Keyte, B. and Locher, D., 2004. The complete lean enterprise. Value stream mapping for administrative and office processes. New York: Productivity Press.

Kroemer, K.H.E. and Grandjean, E., 1997. Fitting the task to the human. 5th ed. London: Taylor \& Francis.

Liker, J.K., 2004. The Toyota way - 14 management principles from the world's greatest manufacturer. New York: McGraw-Hill.

Mathiassen, S.E. and Svendsen, S.W., 2009. Systematic and random errors in postures percentiles assessed from limited exposure samples. In: 17th world congress on ergonomics, IEA 2009, Beijing.

National Research Council (NRC), 2001. Musculoskeletal disorders and the workplace: low back and upper extremities. Washington, DC: National Academy Press.

Neumann, W.P., et al., 2006. Production system design elements influencing productivity and ergonomics - a case study of parallel and serial flow strategies. International Journal of Operations \& Production Management, 26, 904-923.

Nordander, C., et al., 2009. Risk of musculoskeletal disorders among females and males in repetitive/ constrained work. Ergonomics, 52 (10), 1226-1239.

Ostensvik, T., et al., 2008. A search for risk factors of upper extremity disorders among forest machine operators: a comparison between France and Norway. International Journal of Industrial Ergonomics, 38, 1017-1027.

Ratzon, N.Z., et al., 2000. Musculoskeletal symptoms among dentists in relation to work posture. Work, 15 (3), 153158.

Rolander, B., 2010. Work conditions, musculoskeletal disorders and productivity of dentists in public dental care in Sweden. Does dentists working smarter instead of harder? Thesis (PhD). Linköping University.

Rolander, B., et al., 2005. Perceived contra observed physical work load in Swedish dentists. Work, 25 (3), 253-262.

Rundcrantz, B.L., Johnsson, B., and Moritz, U., 1990. Cervical pain and discomfort among dentists. Epidemiological, clinical and therapeutic aspects. Part 1. A survey of pain and discomfort. Swedish Dental Journal, 14 (2), 71-80.

Wells, R., et al., 2007. Time - a key issue for musculoskeletal health and manufacturing. Applied Ergonomics, 38 (6), 733-744.

Westgaard, R.H. and Winkel, J., 2011. Occupational musculoskeletal and mental health: significance of rationalization and opportunities to create sustainable production systems - a systematic review. Applied Ergonomics, 42 (2), 261-296.

Wild, R., 1995. Production and operations management: text and cases. 5th ed. London: Casell.

Winkel, J. and Westgaard, R.H, 1992. Occupational and individual risk factors for shoulder-neck complaints. Part 2. The scientific basis (literature review) for the guide. International Journal of Industrial Ergonomics, 10, 85-104.

Winkel, J. and Westgaard, R.H., 1996. A model for solving work related musculoskeletal problems in a profitable way. Applied Ergonomics, 27 (2), 71-77. 